\title{
LA PERONIZACIÓN DE LOS UNIVERSITARIOS COMO CATEGORÍA NATIVA (1966-1973)
}

\author{
The peronization of the university actors as a native category (1966-1973)
}

\section{Sergio Friedemann*}

\section{Resumen}

Si en 1955 el peronismo era insignificante desde el punto de vista de la militancia estudiantil, hacia 1973 concentraba una importante cantidad de activistas y ganaba elecciones en los centros de estudiantes. En consecuencia, no resulta llamativo que se haya analizado esta mutación en términos de peronización. Lo cierto es que más allá de su uso analítico en trabajos actuales sobre el período, se trata de una categoría utilizada por los actores, quienes observaron un creciente apoyo o inserción de los jóvenes universitarios en el peronismo entre 1966 y 1973. En ese sentido, el propósito del artículo es abordar la llamada peronización como categoría nativa, es decir, atender a los puntos de vista de los actores en su situación particular. Serán situadas y matizadas en su contexto de producción nociones como peronización y nacionalización de los universitarios. Se realiza un recorte que integra la obra de intelectuales referentes de la izquierda peronista junto a observaciones de similar tenor presentes en la correspondencia de Juan Domingo Perón durante su exilio, documentación que resulta en parte inédita y ha sido recolectada recientemente. Conjuntamente, se utilizan otras fuentes primarias como entrevistas, publicaciones periódicas y documentación institucional.

$$
<\text { Peronización }><\text { Universidad }><\text { Años sesenta }><\text { Peronismo }>
$$

\footnotetext{
Abstract

If in 1955 Peronism was insignificant from the point of view of student militancy, by 1973 it concentrated a large number of activists and won elections in student centers. Consequently, it is not surprising that this transformation has been conceptualized as peronization. The fact is that beyond its analytical use in current works on the period, this is a category composed initially by the actors, who observed a growing support or insertion of university students in Peronism between 1966 and 1973. In this regard, the purpose of the article is to address the so-called peronization as a native category. That is, to attend to the points of view of the actors in their particular situation. Notions such as peronization and nationalization of university students will be located and nuanced in their context of production. This article is focused on the work of intellectual referents of the left-wing Peronism together with analyses of similar tenor on the correspondence of Juan Domingo Perón during his exile, documentation that is partially unpublished, and has been recently collected. Moreover, other primary sources are used, such as interviews, newspapers, and institutional documentation.

$$
<\text { Peronization }><\text { University }><\text { Sixties }><\text { Peronism }>
$$

Recibido: 26/05/2017 // Aceptado: 14/07/2017

* Lic. en Ciencia Política y Doctor en Ciencias Sociales (UBA). Becario Postdoctoral del CONICET en el Instituto de Estudios Iniciales (UNAJ). Miembro del Programa de Estudios sobre la Universidad Pública del Instituto de Investigaciones Gino Germani (UBA). Docente regular de la Carrera de Sociología, Facultad de Ciencias Sociales (UBA). ser.fri@gmail.com
} 


\section{Introducción}

En 1973 la Juventud Universitaria Peronista (JUP) ganaba la mayoría de las elecciones a los centros de estudiantes y el peronismo mostraba una inédita actividad en universidades públicas y privadas del país. Esta situación contrastaba con lo sucedido años atrás: el movimiento estudiantil argentino fue mayormente antiperonista cuando se produjo el golpe de Estado a Perón en 1955. No debería sorprender, por tanto, que se haya analizado esta transformación con la noción de peronización de los universitarios. Lo cierto es que más allá de su uso analítico en la bibliografía sobre el tema, se trató de una categoría utilizada por determinados actores, quienes observaron un creciente apoyo o inserción de los jóvenes universitarios en el peronismo, sobre todo entre 1966 y 1973.

Luego de algunos trabajos pioneros que han enfocado el asunto desde una perspectiva muy general (Barletta \& Tortti 2004; Barletta 2000; Ramírez 1999), en la última década han sido los estudios de caso los que han mostrado cómo la peronización se produjo en algunas experiencias particulares (Chama, 2006; Dip, 2017; Ghilini \& Dip, 2015; Reta, 2009; entre otros). En contraste, una serie de trabajos recientes centrados en las dinámicas del conflicto callejero protagonizado por el movimiento estudiantil, han tendido a negar que la llamada peronización hubiera sucedido, adjudicando al fenómeno del '73 la característica de la disrupción (Califa, 2016; Bonavena, 2014; Millán, 2016). Consideramos que el debate no resulta fructífero en caso de plantearse en términos dicotómicos, y que el signo disruptivo que envolvió al regreso del peronismo al gobierno durante la llamada "primavera camporista" no niega necesariamente el carácter procesual y la existencia misma de la peronización de los universitarios durante los años sesenta y comienzos de los setenta. Aun así, en lugar de intentar saldar la controversia en los términos indicados, a saber, buscando determinar el grado de peronización o comparando la importancia de las agrupaciones peronistas respecto a otros espacios políticos, nos proponemos analizar el fenómeno desde otra perspectiva. El propósito de este trabajo es atender a la peronización desde los usos y puntos de vista de los actores en su situación particular. Al mismo tiempo matizaremos los sentidos de las categorías de peronización y nacionalización, que, si bien en ciertos casos aparecen como sinónimos, algunas de las fuentes consultadas muestran una diferenciación que merece ser expuesta.

El trabajo busca avanzar sobre una investigación previa que dio lugar a una tesis doctoral, y se enmarca en una investigación actual sobre las transformaciones del peronismo en los años sesenta y particularmente sobre documentación inédita perteneciente al exilio de Juan D. Perón. La tesis estuvo centrada en un proyecto de reforma universitaria impulsado por la izquierda del peronismo, que se comenzó a institucionalizar desde mayo de 1973 y a través de avances, resistencias y retrocesos, fue finalmente dejada de lado en septiembre de 1974 bajo una nueva intervención durante el gobierno de Isabel Perón. La investigación buscó a su vez dar cuenta de las condiciones previas que hicieron posible la emergencia de un proyecto de universidad alternativo durante los años sesenta. En esa búsqueda, la idea de peronización se manifestó como variable explicativa cuya potencialidad, sostenemos, no debe ser dejada de lado. Aun así, 
algunos reparos actuales desde los estudios históricos sobre el movimiento estudiantil estimularon las presentes reflexiones y su abordaje desde fuentes que en algunos casos resultan novedosas.

Alo largo del artículo, partiremos de considerar algunos elementos introductorios para la comprensión del fenómeno, poniendo el foco en el surgimiento de las agrupaciones peronistas en los años sesenta y en la perspectiva del gobierno nacional del '73 a la hora de otorgar protagonismo a la juventud universitaria, y con ella especialmente a la llamada "tendencia revolucionaria del peronismo". A continuación, presentaremos sintéticamente los usos analíticos de la categoría de peronización en la bibliografía especializada, a partir de los cuales es posible inferir dos posiciones contrastantes en el debate académico. Luego, identificaremos los usos nativos de la categoría en un conjunto de actores involucrados en el proceso que ellos mismos nominaban como peronización. Para no excedernos en los alcances de un artículo, privilegiamos la mirada de quienes habrían observado dicho fenómeno mientras buscaron fortalecerlo. En esa búsqueda, realizamos un recorte que incorpora referentes del peronismo tanto del mundo intelectual y universitario como de la política. Serán observadas en primer lugar las intervenciones de miembros de las llamadas Cátedras Nacionales de la Facultad de Filosofía y Letras. Luego, las de algunos intelectuales referentes de la izquierda peronista ${ }^{1}$ que fueron considerados como los "padres fundadores" de un campo político-intelectual, como John William Cooke, Juan José Hernández Arregui, Arturo Jauretche y Rodolfo Puiggrós. El caso de Puiggrós, que adquiere relevancia por tratarse de quien fuera elegido rector de la Universidad de Buenos Aires en mayo de 1973, será expuesto en un último tramo del trabajo dedicado a la correspondencia con Juan Domingo Perón, junto a otras epístolas recibidas y enviadas durante su exilio por parte del líder del peronismo. Dicha documentación resulta en parte inédita y ha sido recolectada recientemente. ${ }^{3}$

\section{La universidad del '73 como punto de llegada de un proceso}

En 1951, en plena campaña electoral por su reelección presidencial, y con la inauguración del voto femenino, Perón decía lo siguiente: "la primera elección la gané con los hombres, la segunda será con las mujeres y la tercera [la ganaré] con los niños". ${ }^{4}$ No sabía, al enunciar la profética frase, que iba a ser destituido del mandato presidencial debiendo abandonar el país durante un largo exilio.

\footnotetext{
1 A lo largo del texto, utilizamos la categoría analítica de izquierda peronista para dar cuenta de una zona político-intelectual de múltiples manifestaciones que, conservando cierta heterogeneidad, formaban parte de la cultura política de izquierdas, incorporando categorías y horizontes propios del socialismo y la tradición marxista mientras asumían su pertenencia al movimiento peronista (Friedemann 2016a).

2 La expresión es de Adriana Puiggrós (2010) y coincide con otros testimonios recolectados entre 2008 y 2013 respecto al rol formativo ejercido por esos intelectuales en la juventud peronista de los años sesenta y setenta.

3 En ese sentido, este artículo es también una primera aproximación a dichas fuentes, cuyo análisis profundizaremos en futuros trabajos. Agradecemos al Instituto Hoover de la Universidad de Stanford, California, por el apoyo brindado para la estancia de investigación realizada en enero de 2017.

4 "La primera presidencia - LVIII", Primera Plana, 17 de enero de 1967. Citado por Page (1984: 300).
} 
Un primer intento de golpe de Estado se produjo en junio de 1955, aquel que incluyó un bombardeo en Plaza de Mayo, y aunque no fue exitoso, la posibilidad de una nueva tentativa estaba a la orden del día. El gran clivaje del movimiento estudiantil, a diferencia de lo que sucedía en otros espacios sociales, no era el de peronismo-antiperonismo. El debate se daba, en cambio, entre golpistas y antigolpistas. Los primeros creían que el peronismo era una dictadura y debía ser destituida bajo cualquier metodología, y los segundos, aunque eran opositores, no veían con buenos ojos la intentona de un golpe de Estado. ${ }^{5}$ Lo cierto es que buena parte del movimiento estudiantil reformista festejó el golpe de septiembre y, en el caso de la UBA, participó de un programa de gobierno universitario encabezado en primera instancia por José Luis Romero. ${ }^{6}$

En 1973, en cambio, las agrupaciones que seguían levantando las banderas de la reforma universitaria, como el Partido Comunista que dirigía el Movimiento de Orientación Reformista (MOR), y los radicales de Franja Morada, iban a apoyar la intervención peronista de las universidades nacionales. La Juventud Universitaria Peronista (JUP), creada en abril bajo conducción montonera, y como confluencia de agrupaciones peronistas más pequeñas, se iba a llevar la victoria en la mayoría de las elecciones a los centros de estudiantes realizadas ese año.

En síntesis, en 1955 el peronismo era prácticamente insustancial desde el punto de vista de la militancia universitaria, pero hacia 1973 la Juventud Universitaria Peronista (JUP) fue la principal fuerza política de los estudiantes. En algún momento entre esos años, como discurso antagonista a la "desperonización" emprendida en primer término por la autodenominada "revolución libertadora" y continuada por gobiernos civiles y militares, surgió la noción de "peronización". La misma se refería no tanto a los grupos sociales que habían sido peronistas y lo seguían siendo, como los obreros, sino principalmente a aquellos sectores medios que en su gran mayoría habían ensanchado el antiperonismo de la década del '45: intelectuales, profesionales y estudiantes universitarios.

Se trata de un período signado por la radicalización política en el que la revolución cubana jugó un rol fundamental. Otra serie de fenómenos de escala trasnacional resultan asimismo significativos para el caso que estudiamos. El surgimiento de una "nueva izquierda" y fracturas en los partidos de la izquierda tradicional, la confluencia del marxismo con otras tradiciones de pensamiento como el nacionalismo, el humanismo, el existencialismo y el catolicismo, el surgimiento de un cristianismo revolucionario, las

\footnotetext{
5 "Las corrientes golpistas plantearon la militancia obligatoria, que era un poco la militancia en la agitación golpista, el rol que le tocaba al movimiento estudiantil hegemonizado por este sector, y los frondicistas que habíamos tenido la iniciativa de fundar MUR (el Movimiento Universitario Reformista) nos oponíamos a esa cláusula”. Testimonio de Julián Gadano en Toer (1988: 91).

6 Según Ernesto Laclau, elegido en 1956 presidente del Centro de Estudiantes de Filosofía y Letras, el nombramiento de Romero resultó de una propuesta de la FUBA, incluso una "imposición" del movimiento universitario (Toer 1988, p.60). Otro testimonio indica la participación política de los estudiantes en ese marco: "Cuando cayó Perón y José Luis Romero fue rector, muchos de nosotros participamos bastante cerca del rectorado". Testimonio de Miguel Murmis en Toer (1988: 16).
} 
revueltas estudiantiles alrededor del ' 68 y una fuerte ruptura generacional, fueron algunos de los sucesos que tuvieron su variante local y que impactaron en las transformaciones de la sociedad argentina, de la universidad y del peronismo. El golpe de Estado de 1966, el surgimiento de la CGT de los Argentinos en 1968 y el Cordobazo de 1969, son tres de los principales hitos que no pueden dejar de ser considerados para el estudio que aquí presentamos. En buena medida, el surgimiento y desarrollo de agrupaciones estudiantiles peronistas, y la llamada peronización de los universitarios, sucedió a la par de otros procesos concatenados: radicalización e izquierdización de amplios sectores sociales y espacios políticos de tradiciones diversas. ${ }^{7}$

\section{Breve síntesis sobre el surgimiento y desarrollo de las agrupaciones peronistas (1966-1973)}

Como veremos, la peronización fue un proceso observado sobre todo a partir de 1966 y con mayor desarrollo desde 1969. Sin embargo, después del golpe de 1955 las fuerzas reformistas no cesaron de distinguirse por su posición frente al peronismo. A los más antiperonistas se les comenzó a enfrentar un sector de la izquierda que se resistía a la discriminación ideológica que impedía a los peronistas presentarse a concursos docentes. ${ }^{8}$ Aunque el peronismo no era todavía una fuerza de magnitud en el ámbito universitario, no todos mantuvieron una actitud beligerante similar a la del período previo a su derrocamiento. ${ }^{9}$ Pequeña muestra de ello es que el IV Congreso de la FUA, hegemonizado por la izquierda reformista y celebrado en Córdoba en octubre de 1959, iba a pedir por la legalización de las "fuerzas proscriptas" (Ceballos, 1985: 32).

Hasta 1966, las agrupaciones se dividían centralmente en reformistas, humanistas e integralistas. Pero luego de aquel año comienza la "partidización" de la política

\footnotetext{
Sobre los tópicos mencionados y su impacto en el peronismo y las izquierdas, puede consultarse una extensa bibliografía. (Tortti 2002; De Amézola 1999; De Riz 2000; Terán 1991; Bozza 2001; Ponza 2008; Sigal 1991; Altamirano 1992; Donatello 2010; Lanusse 2005; Acha 2009; Brennan 1996; Georgieff 2009).

8 Como observa Pablo Buchbinder (2005) frecuentemente se ha exagerado en torno a los alcances de la llamada modernización durante el período que se abre en 1955. El art. 32 del decreto $\mathrm{N}^{\mathrm{o}} 6403$ del 23/12/1955 indicaba los requisitos que debían satisfacer aquellos profesores que se presentasen a los concursos. Además de los requisitos "generales" ("Conducta moral inobjetable" y cuestiones referidas a los antecedentes académicos), existían dos requisitos llamados "especiales". El primero de ellos indicaba que no serían admitidos a los concursos aquellos que hubieran realizado "actos positivos y ostensibles" a favor de "doctrinas totalitarias adversas a la dignidad del hombre libre y a la vigencia de las instituciones republicanas", el cual dejaba un margen amplio de arbitrariedad en cuanto a su interpretación pero que fácilmente podía ser aplicado para aspirantes pertenecientes al Partido Comunista. Para los profesores peronistas quedaba reservado el segundo de los "requisitos especiales", que no daba lugar a tal hermenéutica: "No serán admitidos tampoco al concurso, quienes en el desempeño de un cargo universitario, de funciones públicas o de cualquier otra actividad, hayan realizado actos positivos y ostensibles de solidaridad con la dictadura (...)". "La dictadura" y "el régimen depuesto", eran entre otras las formas que utilizaba la dictadura militar de Lonardi y Aramburu para referirse al gobierno peronista en el marco de la prohibición dictada por ellos mismos de nombrar a ese gobierno. El texto del cuerpo legal junto a otras normativas y discursos de las autoridades puede consultarse en La Revolución Libertadora y la universidad, 1955-1957. Ministerio de Educación y Justicia, 1957.

9 Sobre este punto, ver testimonios de Murmis y Laclau, en Toer (1988), y Ceballos (1985).
} 
universitaria (Barletta \& Tortti 2004; Krotsch, 2002). Nuevos actores se sumaban a la política estudiantil, y en mayor medida que en el pasado, con consignas que trascendían lo universitario. Las agrupaciones tendrían a partir de ahora una vinculación más directa con fuerzas políticas nacionales.

En un lapso de aproximadamente dos años surgieron las más importantes agrupaciones peronistas del período, junto a otras más pequeñas. La primera que tuvo un importante peso entre la militancia universitaria fue el Frente Estudiantil Nacional (FEN), formada con ex militantes del socialismo y del comunismo, y cuyo principal dirigente fue Roberto Grabois. ${ }^{10}$ Creada en 1965 en la ciudad de Rosario, se expandió por varias universidades nacionales, incluida la UBA. ${ }^{11}$ Se nutrió mayoritariamente de estudiantes y grupos que provenían de la izquierda universitaria, históricamente reformista, pero que realizaron una lectura crítica respecto de la posición asumida en el pasado frente al peronismo. ${ }^{12}$ En una segunda etapa de la agrupación, el FEN se fusionó con Guardia de Hierro adoptando el nombre de Organización Única para el Trasvasamiento Generacional, asumiendo posiciones que la llevaron a enfrentarse a la izquierda peronista durante 1973-1974. ${ }^{13}$

Además del FEN, se destacan la Federación Universitaria de la Revolución Nacional (FURN), acotada a la ciudad de La Plata ${ }^{14}$, y la Corriente Estudiantil Nacionalista Popular (CENAP) de la Universidad de Buenos Aires. ${ }^{15}$ Esta formó parte a su vez de la

${ }^{10}$ Grabois provenía del Partido Socialista de Vanguardia, que había surgido como escisión del socialismo, apoyaba fervientemente la revolución cubana y se inclinaba a tejer alianzas con el peronismo (Tortti 2007). Dentro del socialismo universitario generó tensiones entre quienes estaban más cerca de una alianza con los comunistas y quienes proponían una línea "nacional-popular". También el Partido Comunista sufrió rupturas relacionadas con el posicionamiento frente al peronismo en un contexto en el que buena parte de los trabajadores, lejos de "desperonizarse", conservaban una identificación política peronista. Sobre las rupturas al interior de los partidos socialista y comunista, pueden consultarse los trabajos de María Cristina Tortti (2002, 2007; entre otros)

${ }^{11}$ Durante el segundo semestre de 1968 se realizaron elecciones clandestinas al Centro de Estudiantes de Ciencias Económicas (UBA), en las que el FEN obtuvo la victoria por una mayoría de casi 2000 votos frente a 1000 de las otras tres listas sumadas. "La semana estudiantil", Semanario de la CGT de los Argentinos, números 30 y 39.

${ }^{12}$ Puede consultarse bibliografía específica sobre el FEN como un caso paradigmático del proceso de “peronización” de los universitarios (Anchou 2007; Reta 2009; Ruiz \& Vargas 2013).

${ }^{13}$ A pesar de ello no debe concluirse que sea parte de la derecha peronista. No expresa una política equivalente a la del Comando de Organización (CdO) y la Concentración Nacional Universitaria (CNU), organizaciones que actuaron en conjunto con la triple A en la persecución de militantes de izquierda. En todo caso, intentó ubicarse en una posición centrista frente a las disputas entre los extremos. Aun así, su enfrentamiento con Montoneros la llevó a apoyar la intervención de Ottalagano en la UBA.

${ }^{14}$ Se conformó en 1966 ligada a los intentos del Movimiento Revolucionario Peronista (MRP) por articular la acción de la Juventud Peronista de La Plata con el movimiento estudiantil universitario. El MRP había sido creado en 1964 por Héctor Villalón y Gustavo Rearte, quedando este último a cargo de la Juventud Revolucionaria Peronista (JRP). Como escisión de FURN surgió más tarde la Federación de Agrupaciones Eva Perón (FAEP): la primera tejió vínculos con Montoneros y la segunda con las FAR, y cuando estas se unificaron en 1973 también lo hicieron FURN y FAEP bajo el nombre de JUP. Para un abordaje más desarrollado de estas agrupaciones, nos remitimos a los documentados trabajos de Magdalena Lanteri (2010) y de María Fernanda Simonetti (2002).

${ }^{15}$ De la CENAP participaron agrupaciones de diferentes facultades, como la Tendencia Universitaria 
Federación Argentina Nacional de Estudiantes Peronistas (FANDEP), que intentó articular a las diferentes agrupaciones que empezaban a surgir en diversas carreras, facultades y universidades del país, nacionales y también católicas. Agrupaciones cristianas, que ya tenían existencia en las universidades nacionales, sobre todo en el interior del país y en universidades privadas, atravesaron transformaciones que las acercaron al peronismo en el marco de la renovación del catolicismo tras el Concilio Vaticano II. Entre las conformaciones católicas se destacaba el Integralismo, muy fuerte en el interior del país y que fue semillero de muchos dirigentes y militantes de Montoneros. ${ }^{16}$ Otra agrupación de inspiración cristiana, aunque con presencia no exclusivamente universitaria, fue la Juventud Argentina por la Emancipación Nacional (JAEN). ${ }^{17}$

En agosto de 1968, una serie de encuentros producidos en Rosario, aprovechando una reunión de la Federación Universitaria Argentina (FUA), expresaba el estado de situación en el que se perfilaban múltiples y dispersas agrupaciones peronistas. Quincuagésimo aniversario de la reforma universitaria de Córdoba, fue un año de fuertes movilizaciones y de intentos de confluencia de esos espacios peronistas, e incluso de las primeras acciones conjuntas entre izquierda reformista y peronismo. ${ }^{18}$ En un documento firmado en conjunto aparecían, además de las tradicionales agrupaciones reformistas, la Franja Morada creada un año antes y las peronistas FEN, FANDEP, FURN, entre otros grupos más pequeños y el ya mencionado Integralismo. ${ }^{19}$ Este último conformó junto al Humanismo de Buenos Aires la Unión Nacional de Estudiantes (UNE), posicionándose frente a la dictadura, al imperialismo de Estados Unidos y manifestando su apoyo a la CGT de los Argentinos. ${ }^{20}$ También se conformó la Mesa Nacional Provisoria del Peronismo Universitario, "encargada de coordinar la acción del peronismo en el campo universitario y de consolidar una estructura organizativa". ${ }^{21}$

Junto a las mencionadas hasta aquí, surgieron también agrupaciones peronistas más pequeñas, localmente situadas. Pero hasta 1972-1973 fueron UNE, FEN, FANDEP y FURN las más importantes expresiones del peronismo universitario. Llegando a 1973, la única novedad de relevancia fue, en primer lugar, el alejamiento de FEN de las agrupaciones que se radicalizaron hacia un discurso peronista de izquierda. Y en segundo término la conformación de la nueva JUP ligada a Montoneros en abril de ese

Popular de Arquitectura y Urbanismo (TUPAU) cuyo accionar tuvo una continuidad en 1973. Otra agrupación localizada en una facultad fue la Agrupación de Estudiantes Peronistas de Filosofía y Letras.

${ }^{16}$ Sobre el rol de las agrupaciones católicas en la conformación de Montoneros ver las miradas en algunos puntos divergentes de Lanusse (2005) y Donatello (2010).

${ }^{17}$ Fundada en 1967, entre otros, por Rodolfo Galimberti y Augusto Pérez Lindo y que iba a adherir a una declaración de docentes peronistas, muchos de los cuales formaron parte de las Cátedras Nacionales. "Sociología: Instrumento de conocimiento y de lucha". En Cristianismo y Revolución No 22, diciembre de 1969, p. 6. Para una reconstrucción bien documentada de JAEN y su relación con Montoneros, puede consultarse la tesis doctoral de Julieta Bertoletti (2010).

${ }^{18}$ Acerca de la agudización de la lucha estudiantil durante 1968 ver, por ejemplo, Bonavena y Millán (2007).

${ }^{19}$ Semanario de la CGTA No 17 del 22 de agosto de 1968.

${ }^{20}$ Semanario de la CGTA No 17 del 22 de agosto de 1968.

${ }^{21}$ Documento citado en Hernández Arregui. (2011a, 406). 
año con el propósito de articular a todas las agrupaciones de la izquierda peronista, y con la implícita intención de que esto sucediera bajo la conducción montonera. ${ }^{22}$

Es decir que si tras 1955 las principales agrupaciones estudiantiles eran las humanistas, integralistas y reformistas, durante década del sesenta se producen fraccionamientos internos a esos espacios que fueron conformando la izquierda peronista universitaria, mayoritaria en 1973. Los pequeños espacios del peronismo histórico continuaron una genealogía similar, izquierdizándose algunos de ellos ${ }^{23}$, pero también sobrevivieron espacios de la derecha peronista que entre 1973 y 1976 se expresaron en la Concentración Nacional Universitaria (CNU) y el Comando de Organización (CdO) y que tuvieron una activa participación junto con la Alianza Anticomunista Argentina (triple A) en la persecución de los grupos de izquierda, sean o no peronistas (Besoky 2013).

\section{Hacia la reforma del '73. ¿La peronización como condición de posibilidad?}

Tras el regreso del peronismo al gobierno, a fines de mayo de 1973, las universidades nacionales fueron intervenidas por un decreto firmado por el presidente Héctor Cámpora y el ministro de Cultura y Educación Jorge Alberto Taiana. La normativa del ejecutivo se fundamentaba en la "crisis por la que atraviesa la Universidad Argentina al reflejar en el plano cultural la dependencia económica y política que sufriera el país" y en "que la Liberación Nacional exige poner definitivamente las Universidades Nacionales al servicio del pueblo". Según el decreto, debían reformularse los objetivos, contenidos y métodos de enseñanza, estableciendo un "régimen transitorio de gobierno" hasta tanto se logre un nuevo ordenamiento legal. ${ }^{24}$ Así se daba inicio a un proceso de institucionalización de un proyecto de reforma universitaria que se desarrollará parcialmente, resultará inconcluso y abruptamente interrumpido desde septiembre de 1974 durante la llamada "Misión Ivanissevich". ${ }^{25}$

\footnotetext{
${ }^{22}$ Conforman inicialmente la JUP en la reunión del 9 de abril de 1973 delegaciones de distintos puntos del país. De la ciudad de Buenos Aires firman: AEP (Agrupación Estudiantil Peronista); CUP (Coordinadora Universitaria Peronista: BAPCE, BAPDE, BAPI, CENaP, CEP, FANDEP, GUP, Comando de apoyo al FJL); FORPE (Fuerza para la organización revolucionaria del Peronismo); FAN (Frente de Acción Nacional); MIF (Movimiento Independiente Facultad); y MSCD (Movimiento Social Cristiano de Derecho). De resto del país, se pueden destacar FURN y FAEP de La Plata; la JUP de Rosario; el consejo provisorio de la JUP de Córdoba; entre otros grupos de Mar del Plata, Santa Fe, Entre Ríos, Chaco, Corrientes y Misiones entre los que sobresalen agrupaciones del Integralismo. Reproducimos las firmas tal como aparecen en el documento, publicado en la revista Envido, № 9, mayo de 1973.

${ }^{23}$ Como la también llamada Juventud Universitaria Peronista (JUP) que fue fundada en 1962 con orígenes en la Confederación General Universitaria (CGU) de los años cuarenta. Homónima de la creada por Montoneros una década más tarde, la JUP seguía los lineamientos de la Acción Revolucionaria Peronista (ARP) de John William Cooke y aglutinaba a espacios peronistas de distintas facultades y universidades del país (Recalde \& Recalde 2007).

${ }^{24}$ Decreto No 35 del 29/5/73. Boletín oficial de la República Argentina del 13/7/73.

${ }^{25}$ Para un desarrollo completo de lo que aquí sintetizamos, nos remitimos a nuestra tesis doctoral (Friedemann 2015). Asimismo, una publicación reciente avanza sobre el final de esa reforma cuando la derecha del peronismo desplaza a la izquierda del gobierno de la Universidad de Buenos Aires, interrumpiendo el proceso de normalización institucional y anulando las medidas tomadas desde mayo de 1973 (Friedemann 2016b).
} 
La reforma fue impulsada por un conjunto de actores y figuras inscriptas en diferentes variantes de la izquierda peronista, y la propuesta contemplaba transformaciones importantes en vectores clave de lo que constituye una política pública universitaria. Partimos de considerar el punto de vista de los reformadores, pero sintetizamos sus propuestas a través de tres dimensiones de análisis que hemos construido en una investigación previa: 1) el sujeto de la educación universitaria, como propuesta de democratización en el acceso donde la presencia de las clases trabajadoras cobraba centralidad; 2) el sentido de la formación y la producción de conocimiento, que debía estar en sintonía con las necesidades y prioridades nacionales y especialmente de los grupos sociales más postergados; 3 ) la propuesta político-pedagógica, que planteaba una modificación de los métodos y contenidos de la enseñanza, reemplazando planes de estudio y postulando un rol más activo del estudiante en la relación pedagógica. La JUP tuvo un protagonismo no despreciable en la formulación del proyecto de reforma y en la designación de autoridades. Las agrupaciones de las que se había nutrido, como la FURN de La Plata, pudieron hacer valer varios años de construcción de propuestas para una "nueva universidad". Algunas de las transformaciones impulsadas avanzaron más que otras, y, en todo caso, las resistencias que se le opusieron lograron finalmente imponerse tras la intervención de Isabel Perón.

Antes de ello, cuando el peronismo retornó al gobierno en 1973, existió efectivamente una voluntad política de incorporar a los sectores juveniles que los actores ubicaban como "tendencia revolucionaria del peronismo" a la planificación y ejecución de políticas universitarias. La izquierda peronista, entonces, tendría un lugar relevante. Como rector de la UBA fue elegido Rodolfo Puiggrós, un historiador marxista que había sido expulsado del Partido Comunista en los años cuarenta por su acercamiento al peronismo.

Si algo había facilitado una mayor adhesión de los sectores medios universitarios al peronismo, era justamente su capacidad de asimilar muchos postulados provenientes de la tradición política de izquierdas e incluso de la teoría marxista durante esos años. Las políticas públicas universitarias, siguiendo ese análisis, no se iban a identificar linealmente con las del peronismo clásico. En efecto, formaron parte de una reforma donde convergían elementos de diferentes tradiciones: del primer peronismo y del nacionalismo, pero también de la izquierda y del reformismo, del tercermundismo y las filosofías/pedagogías de la liberación e incluso del cristianismo (Friedemann 2015)

Las transformaciones del peronismo y las que manifestaba el propio Perón en los años sesenta impactaron en las nuevas interpretaciones respecto de ese movimiento político a cargo del gobierno, dando lugar a tensiones y disputas. Respecto de los propios desplazamientos del líder justicialista, no debe descartarse una revisión crítica en materia universitaria. Según quien fuera su médico personal y Ministro de Cultura y Educación en 1973-1974, durante su exilio Perón había acumulado una experiencia internacional en torno al creciente protagonismo de la juventud, y también acerca de temas universitarios que en las grandes ciudades se habían manifestado altamente conflictivos alrededor de 1968. Escribe Jorge Taiana que Perón había analizado los 
enfrentamientos en gran parte del mundo entre los estudiantes y la policía, lo que lo llevó a elegir "el encauzamiento de los jóvenes dentro de un marco constructivo" (Taiana, 2000: 162). La misma fuente indica que Perón había hecho una autocrítica acerca de las políticas universitarias durante su primer gobierno:

De la vida universitaria del período 1946-1955 Perón conservaba un mal recuerdo. Profesores y estudiantes desarrollaron, en gran número, una manifiesta oposición a su gobierno y a su persona. Los pocos que comprendimos la amplitud y profundidad del proceso justicialista y soslayamos los errores y las desviaciones de superficie, recordamos muy bien la difícil tarea de actuar y gobernar las universidades de aquella época. Hombres capaces se retraían, no participaban en los concursos y las designaciones de profesores solían realizarse con dificultades notorias. Los estudiantes, casi todos no peronistas, emprendieron una oposición decidida y a veces muy violenta (Taiana, 2000: 162).

La idea de una autocrítica por parte de Perón reaparece en el testimonio de Alcira Argumedo. La ex integrante de las Cátedras Nacionales afirma que pudo entrevistarlo en Madrid mientras se desarrollaba esa experiencia y que Perón decía "que la política universitaria había sido pésima... [porque] la gente que se formaba en la universidad se le ponía en contra". ${ }^{26}$

Ambas memorias parecen indicar que la mirada crítica de Perón no ponía en un primer plano los contenidos de las políticas públicas universitarias sino lo que podría considerarse un efecto no deseado de las mismas: el hecho de no haber superado la hostilidad de los universitarios, especialmente de los estudiantes, pero también de los profesores. Es probable que para ganar el apoyo del movimiento estudiantil debía sostenerse en cierto grado la autonomía universitaria y el cogobierno, lo que no había sido una preocupación del gobierno en los años cuarenta. Ahora parecía ser diferente. Según recuerda el hijo del ministro Taiana, que se desempeñó como secretario de su padre:

El objetivo principal, es decir, la idea de mi padre, y que era la idea que tenía Perón también -que en la práctica termina mal. Pero digamos la idea de ellos en el '72, '73 era que uno de los problemas que había tenido el primer peronismo era su enfrentamiento con la juventud universitaria; con la juventud clase media, con los profesionales. Y que este es un daño que lo llevaba a la derrota. Entonces un proyecto nacional y popular debía contar con ese sector. ${ }^{27}$

\footnotetext{
${ }^{26}$ Testimonio de Alcira Argumedo, en entrevista realizada por L. Brugé, el 25 de mayo de 2001. En Un recorrido en la búsqueda de Nos-otros, Escuela de Antropología, Facultad de Humanidades y Artes. Rosario, diciembre de 2005. Año 1 / Número 2.

${ }^{27}$ Entrevista realizada por el autor a Jorge Taiana (h.) el 28 de abril de 2011.
} 
De acuerdo a este testimonio, existió una decisión política explícita por parte de Perón de modificar algunos lineamientos universitarios llevados adelante durante sus primeros gobiernos, lo cual colocaba al ministro Taiana en una función particular:

Que el peronismo había cometido un error importante con los sectores medios en el primer período, se había enemistado, y que entonces en esta segunda etapa había que tener un proceso educativo, cultural más a la izquierda que la tradición del peronismo pero que se forzara en mantener adentro a la juventud creativa, comprometida y con ideas sociales. Esto significaba tener claro que la educación y la cultura iban a estar más a la izquierda que el resto. ${ }^{28}$

Pero no era solamente una cuestión de voluntad política. Si es cierto que existió una resolución de darle un lugar protagónico a la juventud universitaria, lo es también que, para lograrlo, debía contar el gobierno con cierta masa estudiantil que apoyara al peronismo. A modo de hipótesis, puede afirmarse que el hecho de que los mayores hayan observado un proceso de peronización de la juventud durante los años previos se vuelve condición necesaria del proceso abierto con el retorno del peronismo al gobierno. En otras palabras, es difícil suponer que Perón hubiera definido ensayar un proyecto universitario que estuviera "más a la izquierda", una reforma ejecutada con protagonismo del movimiento estudiantil, sin haber confiado en un proceso de peronización de los universitarios. La posterior ruptura entre el líder y la izquierda peronista, como resultado de un proceso político abierto, no debería predisponer el análisis de la situación previa si se quiere evitar todo determinismo teleológico.

\section{La peronización en la producción académica}

La categoría de peronización de los universitarios ha sido útil en las últimas dos décadas para un conjunto de investigaciones que han intentado explicar ese proceso complejo que confluyó en la intensa marea de 1973 (Barletta, 2000; Chama, 2006; Reta, 2008; Ramírez, 1999; Dip, 2017; Barletta \& Tortti, 2004; Ghilini \& Dip, 2015). Los trabajos en general coinciden en marcar el golpe de Estado de 1966 como un "parteaguas", luego del cual surgen una cantidad considerable de agrupaciones universitarias peronistas en distintos lugares del país, en establecimientos públicos y privados. ${ }^{29}$ Como repasamos, se trató de agrupaciones generalmente pequeñas y con intentos de articulación muchas veces fallidos, pero que en los años siguientes desplegarían cierto crecimiento. También aparece el Cordobazo de 1969 como un punto de inflexión para el desarrollo de este proceso.

\footnotetext{
${ }^{28}$ Ibídem. El destacado es nuestro.

${ }^{29}$ Sin menosprecio de ello, el reciente trabajo de Nicolás Dip (2017) se destaca por el análisis de las trayectorias previas de sus principales dirigentes, visualizando las continuidades además de las rupturas que engloban al golpe de Estado de 1966.
} 
La peronización de los años sesenta es definida desde sus primeros usos en el campo de estudios sobre la universidad como un fenómeno novedoso y diferencial. Como destacaron Ramírez (1999) y Barletta (2000), en los años sesenta el peronismo logró captar importantes apoyos del público universitario, a diferencia de lo sucedido veinte años atrás. Parte de la novedad radicaba en que el propio movimiento peronista comenzó a interesarse por ampliar su base de apoyo entre los universitarios, incorporando preocupaciones y consignas propias de la tradición peronista en ese ámbito. ${ }^{30}$

A partir del puntapié brindado por estos aportes, en los últimos años se han desarrollado numerosos estudios de caso que toman como eje la llamada peronización de los universitarios. Algunos acotados a una universidad, otros a determinada agrupación estudiantil, experiencias editoriales e incluso a redes disciplinares y profesionales, son trabajos valiosos porque en su conjunto muestran que se trató de un fenómeno significativo en distintos ámbitos ligados a lo universitario (Chama, 2006; Dip, 2017; Ghilini \& Dip, 2015; Reta, 2009; entre muchos otros).

Confrontando con esos trabajos, un conjunto de investigaciones recientes sobre el movimiento estudiantil, centradas en las dinámicas de conflicto callejero, han afirmado que tal proceso de peronización de los universitarios no tuvo lugar, y que la experiencia del '73 se explica más como un fenómeno disruptivo que como un proceso de mediana duración (Califa 2016; Bonavena 2014; Millán 2016). En esa línea, se ha llegado a afirmar que "los obstinados defensores de la tesis de la peronización" no han podido "recurrir a indicadores empíricos concretos ya que ni en los centros participaban ni en las luchas universitarias del período de conjunto sobresalían los peronistas" (Califa, 2016: 10). En polémica con afirmaciones posiblemente exageradas, como que la identidad reformista "se comienza a resquebrajar inmediatamente de ocurrido el golpe del '55" (Ramírez, 1999: 192), los trabajos referidos caen en otro extremo al subestimar el pasaje de figuras, grupos y sectores sociales de un explícito antiperonismo a un creciente apoyo o comprensión por el movimiento peronista, cuyas reconfiguraciones atravesadas en los años sesenta coadyuvaron a la articulación de elementos izquierdistas con la identidad peronista.

En efecto, en los estudios de caso arriba mencionados se verifica empíricamente el fenómeno de la peronización de universitarios. Afirmar su existencia no implica la necesidad de concluir que el peronismo haya logrado superar en número o importancia al reformismo antes del proceso abierto en 1973. E inversamente, tampoco es prueba suficiente para concluir la ausencia de peronización el hecho de que los peronistas no aparezcan en las noticias referidas a los conflictos callejeros o en las experiencias subrepticias de elecciones a centros de estudiantes en la clandestinidad impulsados por las fuerzas reformistas.

Sin quitar importancia al debate que brevemente hemos sintetizado, consideramos que la polémica respecto de la existencia misma del proceso de peronización no

\footnotetext{
${ }^{30}$ Aunque abocados al ámbito universitario, estos estudios se engarzan con aquellos clásicos que, desde la historia intelectual, habían atendido a la relectura realizada respecto del peronismo en el campo de las ideas políticas de las izquierdas (Altamirano 1992; Terán 1991; Sigal 1991).
} 
enriquece el conocimiento académico sobre el tema si se plantea meramente en términos dicotómicos. El fenómeno abierto a finales de 1972 y comienzos de 1973, en el marco del Gran Acuerdo Nacional impulsado por Lanusse y en la expectativa generada por el regreso de Perón al país, dio lugar a un fenómeno político y social claramente disruptivo que no podía más que impactar en la política universitaria. Montoneros, por entonces la organización más importante de la izquierda peronista, atravesó un proceso que sus propios integrantes calificaron como "engorde" (E. Jauretche, 1997). Pero el proyecto de reforma universitaria impulsado por la izquierda peronista desde la asunción de Cámpora como presidente, difícilmente podría haberse intentado sin que en los años sesenta se hubieran producido las transformaciones que la bibliografía ha abordado como peronización o nacionalización de los sectores medios. En síntesis, por disruptivo que haya sido el fenómeno del '73, resulta difícil comprenderlo sin atender a las transformaciones subjetivas sucedidas en los años sesenta que dieron lugar a novedosas lecturas y expectativas depositadas sobre ese movimiento político. La interpretación "disruptivista" no colisiona con la "tesis de la peronización", y afirmar esta última no implica concluir que la identidad reformista haya sido suplantada por la peronista en las militancias juveniles. En efecto, fruto de la politización y radicalización de la sociedad, las identidades políticas sufrieron transformaciones durante el período de las que no fueron ajenas las agrupaciones universitarias. Esto es observado por Nicolás Dip, para quien el propio peronismo de los años sesenta efectuó una "revalorización de la cuestión universitaria", constituyéndose en un "espacio de militancia legítimo" (Dip 2017, 33). En ese sentido, creemos posible afirmar que hacia 1973 el peronismo no era tan antirreformista como en el pasado, ni el reformismo tan antiperonista.

Sobre este punto, resulta aleccionador el testimonio brindado por dirigentes estudiantiles ante la intervención de 1973. Los radicales de Franja Morada iban a estrechar lazos con la izquierda peronista y apoyar la intervención. Marcelo Stubrin, joven radical y secretario general de la Federación Universitaria Argentina (FUA - Córdoba) se mostró optimista con el proceso que se abría y dispuesto a colaborar con los rectores y decanos: "no permitiremos que el árbol del folklore reformista nos impida ver el bosque, pero defenderemos nuestras posiciones". ${ }^{31}$ La FUA llegó a 1973 dividida, pero también iba a apoyar la intervención el sector de La Plata, controlada por el Movimiento de Orientación Reformista con mayoría del Partido Comunista. ${ }^{32}$ Así lo esperaba la Juventud Universitaria Peronista (JUP) que iba a conducir la FUBA, rebautizada como Federación Universitaria para la Liberación Nacional de Buenos Aires (FULNBA): "la política lanzada es asumida por el conjunto de los estudiantes. Sabemos que los compañeros reformistas reconocen la profundidad del mismo y sabemos que ellos pueden participar para combatir a la oligarquía y el imperialismo". ${ }^{33}$

¿Cómo avanzar en el conocimiento acerca de la llamada peronización sin caer en lecturas dicotómicas y simplificadoras? Creemos que existe una vía aun no explorada

${ }^{31}$ Entrevista a Marcelo Stubrin, Revista Panorama, 7 de junio de 1973.

${ }^{32}$ Entrevista a Jorge Kreyness, presidente de la FUA - La Plata, Revista Panorama, 7 de junio de 1973.

${ }^{33}$ Entrevista a José Pablo Ventura, estudiante de Derecho y cabeza de la JUP - Regional Buenos Aires. Revista Panorama, 7 de junio de 1973. 
para el análisis del fenómeno, enfocándolo desde otro prisma interpretativo. No negamos la validez de centrar los estudios en el sentido de demostrar o refutar la importancia que habría tenido tal proceso, pero proponemos aquí abordar la peronización ya no como categoría analítica sino como categoría nativa. Como se ha propuesto desde un aporte de la antropología social para el estudio de la política, "los científicos sociales a menudo empleamos categorías nativas polisémicas (...) como si fuesen categorías analíticas con un sentido inequívoco", pero los sentidos que les otorgamos unos y otros no resultan necesariamente homogéneos. Por tanto, resulta "imprescindible para nosotros (los analistas), historizar los usos nativos plurales de esas categorías" (Soprano, 2009: 175).

En ese sentido nuestra propuesta no apunta a demostrar el grado de relevancia que tuvo la peronización, ya sea en términos comparativos con agrupaciones juveniles de otros colores políticos, o estableciendo una ajustada periodización que denote en qué momentos tuvo lugar con mayor profundidad. No es cuestión de medir diacrónicamente la peronización, sino de dar cuenta de un fenómeno que los propios protagonistas observaron en su situación particular. Se trata de avanzar en la comprensión del punto de vista de los actores, como se ha propuesto desde un enfoque de tipo etnográfico. En síntesis, la idea de peronización merece también ser abordada desde su existencia genéticamente situada. En este trabajo, ensayamos una primera aproximación al abordaje de la peronización desde la perspectiva de un conjunto de actores que observaron dicho proceso mientras buscaron fortalecerlo.

\section{Los usos nativos de la categoría de peronización}

Más allá de su uso analítico en trabajos actuales sobre el período, la categoría de peronización fue utilizada por los actores que observaron un creciente apoyo o inserción de los jóvenes universitarios en el peronismo. En algunas narrativas sobresale también la idea de nacionalización. Esta última permitió a intelectuales y políticos -generalmente peronistas de una generación mayor- dar cuenta de un proceso de transformación ideológica que observaron en jóvenes universitarios y sectores de izquierda pero que no necesariamente iban a adherir al peronismo. Asuntos como la "toma de conciencia nacional", la "nacionalización mental del estudiantado", o una mayor comprensión por la "cuestión nacional", se utilizaron para dar cuenta de aquellos que, sin integrarse al peronismo, podían comprenderlo de otro modo. Aunque algunos utilizaron ambas categorías como sinónimos, otros expresaron sus matices.

En cualquier caso, fue un proceso observado por los actores y como tal lo abordamos. Una experiencia significativa fue la de las llamadas Cátedras Nacionales de la Facultad de Filosofía y Letras (1967-1971), que no solamente percibieron la llamada peronización y nacionalización, sino que se propusieron fortalecerla desde espacios formativos de las currículas universitarias. También tendremos en cuenta su manifestación en intelectuales distintivos de la izquierda peronista como John William Cooke, Arturo Jauretche, Rodolfo Puiggrós y Juan José Hernández Arregui, quienes reconocen este fenómeno después de 1966. Veremos también que el mismo Perón se mostró entusiasmado, en su escritura epistolar desde el exilio, con las transformaciones 
ideológicas de la juventud universitaria. La observación de dicho proceso por parte de Perón y los peronistas no puede más que haber impactado en la definición política que llevó, en 1973, a que la izquierda peronista encabece una transformación universitaria con protagonismo del movimiento estudiantil.

\section{Las Cátedras Nacionales: "peronización” y "nacionalización” de los estudiantes de Filosofía y Letras}

Las Cátedras Nacionales fueron un conjunto de materias de la Facultad de Filosofía y Letras, que comenzaron a ser denominadas de ese modo por los estudiantes. Se trató de una de las experiencias más visitadas por la bibliografía a la hora de analizar lo que constituyó un creciente apoyo del estudiantado por el movimiento peronista (Dip, 2017; Ghilini, 2015; Mallimaci \& Giorgi, 2007; Moscona, 2010; Recalde \& Recalde, 2007; Rubinich, 1999; entre otros) y a la vez paradigmáticas de aquellas experiencias que a lo largo de los años sesenta configuraron un proyecto de universidad "nacional y popular" que intentó su institucionalización en 1973-1974 (Friedemann, 2017).

Los integrantes de esta red disciplinar proveniente de las humanidades y ciencias sociales también deben ser incluidos en la nómina de intelectuales que se constituyeron en referentes de una izquierda peronista durante el período estudiado. Más allá del análisis que pueda realizarse respecto del rol que habrían cumplido en el llamado proceso de peronización y nacionalización, se trata aquí de explorar los usos nativos de esas categorías en los textos producidos por miembros de este colectivo.

Gonzalo Cárdenas, uno de los titulares de cátedra que, junto con Justino O' Farrell, dieron inicio a esta experiencia en la carrera de Sociología, observaba en 1969 que fue luego del golpe de Estado de 1966 que se crearon las condiciones para acelerar el "proceso de nacionalización de los universitarios", que según su mirada ya había comenzado antes del golpe. Según Cárdenas, la nacionalización es un "hecho irreversible", que contiene y excede a la peronización, en el sentido de que la toma de conciencia nacional no implica necesariamente una incorporación al peronismo:

La nueva situación universitaria, se caracteriza por un lado por la falta de una conducción unitaria, y por el otro por la presencia de agrupaciones estudiantiles de tipo nacionalista, que contienen en su seno militantes peronistas que van creciendo en número y en fuerza paulatinamente. De modo que agrupaciones denominadas humanistas, o reformistas, o ateneístas, o directamente nacionales, son hoy rótulos que no alcanzan a definir exactamente el proceso de nacionalización del estudiantado, aun cuando algunas conducciones todavía se encuentran ligadas a las posiciones previas a la toma de conciencia nacional, no así la masa estudiantil que ha sufrido verdaderamente y en profundidad un nuevo proceso. (...) 


\begin{abstract}
Algunas conducciones fracasan en la adaptación y regresan a las posiciones de origen completamente deterioradas porque no se animan a dar el paso definitivo en su integración al peronismo. ${ }^{34}$
\end{abstract}

Para Cárdenas, la revolución solo es posible en la convergencia entre "capas intermedias" y "clase trabajadora", que se mostró posible a partir del Cordobazo. Para ello, insiste en que resulta indispensable el paso de la militancia estudiantil al peronismo, "el movimiento nacional de masas", para que las luchas contra la dictadura no sean en vano.

Las Cátedras Nacionales tuvieron participación hasta 1971, cuando luego de reiterados conflictos con las autoridades fueron perdiendo sus cargos. Ese año Roberto Carri perdió un concurso de adjunto con Juan Carlos Portantiero, y el de titular que ocupaba Justino O'Farrell se declaró desierto. En un “mensaje a los compañeros”, con tono de despedida, escribía O'Farrell:

En diferentes etapas de nuestras vidas, nos hemos ido integrando al pueblo y descubriendo a la vez que, en sustancia, siempre habíamos estado integrados a él. Un descubrimiento que pudo habernos insumido a nosotros mucho tiempo pero que hoy se realiza, entre los universitarios, con la fuerza y la característica de los desplazamientos colectivos, de los grandes contingentes humanos. ${ }^{35}$

En ese texto, uno de sus iniciadores daba por "liquidada" la experiencia de las Cátedras Nacionales. Un año después, la mayoría de sus integrantes escribía un "documento autocrítico de las ex - cátedras nacionales", donde se iban a considerar expulsados de la universidad. La mirada autocrítica tenía que ver con haberse ubicado, según ellos inconcientemente, en el lugar de vanguardia de la revolución en lugar de dejar que ocupara ese espacio la clase obrera. Los firmantes de este documento se ubicaban en la "alternativa independiente" que proponía entonces el Peronismo de Base, y además de su mirada autocrítica incluían una serie de aciertos: principalmente, el haber contribuido a "la llamada peronización de la universidad" y a "la nacionalización mental de los estudiantes". ${ }^{36}$ Los ex miembros de las Cátedras Nacionales volverían en 1973 a la Universidad de Buenos Aires, ya no como pequeña experiencia contestataria de un puñado de cátedras peronistas, sino como conducción de la Facultad de Filosofía y Letras y del flamante Instituto del Tercer Mundo "Manuel Ugarte". ${ }^{37}$

\footnotetext{
${ }^{34}$ Gonzalo H. Cárdenas. El movimiento nacional y la universidad, Antropología 3er mundo, $\mathrm{N}^{\mathrm{o}} 3$, Año 2, noviembre 1969, pp. 41-63.

${ }^{35}$ Justino O'Farrell. Mensaje a los compañeros, Envido, № 4, septiembre 1971, pp. 74-75.

${ }^{36}$ De base y con Perón. Un documento autocrítico de las ex - cátedras nacionales, Antropología 3 er Mundo, $\mathrm{N}^{\circ} 10$, junio 1972, pp. 27-34.

${ }^{37}$ Sobre las Cátedras Nacionales como "experiencia configuradora" de la Universidad Nacional y Popular de Buenos Aires, nos remitimos a un reciente artículo de nuestra autoría (Friedemann, 2017).
} 


\section{John William Cooke y el abandono del antiperonismo}

Uno de los primeros en observar estas transformaciones en el estudiantado fue John William Cooke, quien, con su incisiva crítica a la conducción local del peronismo, a la que calificaba de "burócrata", contribuyó a delimitar espacios y dirigentes que, si bien asumían la identidad peronista, manifestaban importantes desacuerdos en torno a la coyuntura política abierta por el golpe de Estado de 1966. La mirada sobre la universidad no iba a ser la excepción. Mientras algunas figuras del "neoperonismo" (sectores que Cooke calificaba de burócratas, conservadores y reaccionarios, cuando no infiltrados), callaban ante la intervención universitaria, el dirigente del "peronismo revolucionario" observaba que

El estudiantado no es el mismo de hace diez años, y así como la sobrevivencia del peronismo señala la descomposición del régimen, ese fenómeno no ha pasado inadvertido para una gran masa de estudiantes, que no están aprisionados por las alienaciones de la cultura liberal. (...)

La actitud de una juventud que ha abandonado el antiperonismo de las generaciones anteriores y en lugar de las viejas declaraciones sobre una mítica unidad obrero-estudiantil ahora se une a las causas que defienden los trabajadores; (...) que está buscando la coincidencia con las masas populares, a veces con acierto, otras más torpemente, pero siempre con el espíritu de no aislarse del pueblo, eso es lo que verdaderamente preocupa a la reacción. (Cooke, 2014 [1966]: 86)

Debe tenerse en cuenta que Cooke falleció de cáncer en 1968, por lo que no llegó a vivenciar los mayores alcances del llamado proceso de peronización de los estudiantes. Pero sus observaciones brindan un testimonio temprano acerca del mismo. Otra consideración merece el hecho de que Cooke había brindado conferencias y charlas en distintas universidades del país, como la de Córdoba de 1964 donde también observaba que la generación estudiantil ya no era la misma que en 1945 y 1955, y sugería que la autocrítica de esos sectores era un asunto que ya se encontraba planteado (Cooke, 2015 [1964]: 130).

\section{Juan José Hernández Arregui: la nacionalización del estudiantado y la irrupción del peronismo}

Hernández Arregui fue uno de los profesores peronistas expulsados de sus cátedras en 1955 y que vieron restringido su acceso a concursos. Se convirtió desde entonces en uno de los principales críticos de la falta de "educación política" en los sectores medios, y sus libros iban a constituir una de las principales herramientas para cubrir esa vacancia (Carli 2014). 
Pero en 1969 ya visualizaba un cambio. Afirmaba que "el espíritu crítico penetra [en el estudiante, que] en los umbrales de la lucha anticolonialista, percibe vagamente que la educación recibida marcha a destiempo con el violento hervor social de los acontecimientos" (Hernández Arregui, 2004 [1969]: 146). Un año más tarde, reeditaba La formación de la conciencia nacional. Respecto de la primera edición de 1960, se puede apreciar cómo Hernández Arregui observó una mutación ideológica en los sectores medios, incluidos docentes y estudiantes universitarios. Fue en esa segunda edición de 1970 que incluyó un anexo documental por él comentado, buscando mostrar el llamado proceso de nacionalización a través de diferentes textos de agrupaciones peronistas estudiantiles y docentes, de los miembros de las Cátedras Nacionales y de organizaciones de la izquierda peronista a nivel nacional. Allí, junto a otro tipo de documentos, se manifestaba ya con fuerza la articulación de marxismo y peronismo y la elaboración de un conjunto de propuestas para transformar la universidad. La categoría de nacionalización sobresale en los comentarios del autor (Hernández Arregui, 2011a). ${ }^{38}$

También en su última obra, Peronismo y Socialismo (1972) presentada como un libro de divulgación sin pretensiones teóricas, todavía buscaba dar cuenta de lo que llamó la "nacionalización de la clase media" (Hernández Arregui, 2011b [1972]: 91):

El peronismo, que jamás pudo hacer pie en la Universidad, desde hace pocos años, en un repunte sorprendente, ha irrumpido en las casas de estudios, e incluso, centros de estudiantes que no se declaran partidarios de Perón, en especial los comunistas, marchan con el peronismo y contra el imperialismo (...). La actual generación estudiantil ha dado un paso resuelto hacia la toma de conciencia nacional (Hernández Arregui, 2011b [1972]: 91).

Como puede verse, en el caso de Arregui la categoría más utilizada es la de nacionalización, pero la "irrupción del peronismo" y el "paso hacia la toma de conciencia nacional" son identificadas como partes de un mismo proceso. También se encuentran en su obra una serie de reflexiones en torno a tópicos centrales del proyecto universitario del '73: la puesta en discusión de la idea de autonomía, la revalorización de un contenido político en los planes de estudio, la reivindicación de un pensamiento nacional, la ruptura con organismos internacionales que financiaban planes de investigación, la idea de una educación al servicio de determinados sectores sociales y la enorme importancia del ingreso irrestricto. Asumido el nuevo gobierno peronista, no ocupará cargos de relevancia, pero estará en una terna propuesta por Montoneros para encabezar el Ministerio de Cultura y Educación, y según otras versiones, el rectorado. Será nombrado profesor emérito de la Universidad de Buenos Aires, pero fallecerá un año más tarde perseguido por la triple A.

\footnotetext{
${ }^{38}$ El anexo documental a la segunda edición de La formación de la conciencia nacional consta de 57 páginas en su reedición de 2011.
} 


\section{Arturo Jauretche y la descolonización pedagógica}

Arturo Jauretche publicó Los profetas del odio en 1957, y si bien allí se refirió al rol de las clases medias, y específicamente a los intelectuales, fue en su tercera edición de 1966 que incluyó la segunda parte titulada "la colonización pedagógica", de gran repercusión. ${ }^{39}$

En la introducción escrita en 1966 se refirió Jauretche a la "superestructura cultural", con influencia del pensamiento marxista: "A la estructura material de un país dependiente corresponde una superestructura cultural destinada a impedir el conocimiento de esa dependencia" (Jauretche, 1997: 22). A ese impedimento Jauretche lo llamó "colonialismo mental" y "colonización pedagógica".

Este último concepto lo tomó de Jorge Abelardo Ramos, quien a la vez lo había recuperado del filósofo y pedagogo alemán Eduard Spranger a quien calificaba como "un imperialista alemán” (Ramos, 2014 [1954]: 16). El diagnóstico de Ramos era el de una "devastación espiritual de las nuevas generaciones intelectuales (...). La juventud universitaria, en particular, ha asimilado los peores rasgos de una cultura antinacional por excelencia. Bajo estas condiciones históricas se formó nuestra élite intelectual" (citado por Jauretche, 1997: 98-99). Interesante es destacar la aclaración que el Jauretche de los sesenta realizaba entre paréntesis: "(Recordemos que esto está publicado en 1954 y no corresponde ya a este momento en lo que se refiere a las nuevas generaciones)" (Jauretche, 1997 [1966]: 98). Es decir que, si bien realizó fuertes críticas a las posiciones políticas asumidas históricamente por el estudiantado reformista contra el yrigoyenismo y contra el peronismo, Jauretche observaba, igual que Hernández Arregui, un cambio sustancial al promediar la década del sesenta:

El estudiante se libera del "fubismo"[40] cuando empieza a sentirse hombre antes que estudiante, e hijo del país y hermano de sus hermanos antes que miembro de un sector magistral; cuando el grupo social estudiantil comienza a disolverse en la multitud y sentirse parte de ella, comprendiendo que sólo aprende una técnica que lleva a la profesión, como otras técnicas llevan al oficio o al negocio, a la empresa o a la chacra. En una palabra, cuando se demuele su condición de élite, y se rompe la pretensión tutorial de la "intelligentzia", y el estudiante percibe que él no es la "civilización contra la barbarie", sino parte de una sociedad real que en el dilema se le ha presentado como bárbara. Cuando empieza a pensar como argentino que es estudiante, y no como estudiante, que es además argentino. Recién entonces — creo que ahora ya- perderá esa hosca actitud que lo caracterizó frente a los movimientos auténticos de las masas (...) (Jauretche, 1997 [1966]: 142. El destacado es nuestro).

\footnotetext{
${ }^{39}$ De ese modo, la obra completa quedó titulada Los profetas del odio y la Yapa (Jauretche, 1997).

${ }^{40}$ En referencia a la Federación Universitaria de Buenos Aires, órgano de representación de los centros de estudiantes de la UBA.
} 
Como veremos en breve, Jauretche actuó como conferencista en las universidades, ganando público y aplausos que resultaron una novedad para algunos peronistas que intercambiaron cartas con Perón. En 1973 ocuparía la presidencia de la editorial universitaria de la UBA, que amanecería en mayo de ese año pintada con la leyenda "EUDEBA popular y Montonera". ${ }^{41}$ Jauretche fallece en 1974, el mismo año que Hernández Arregui y Perón.

\section{La peronización de universitarios e intelectuales en la correspondencia de Perón}

Entre 1955 y 1973, durante los casi 18 años de exilio, Perón dedicó gran parte de su tiempo a la correspondencia. El género epistolar es una forma de comunicación que surge principalmente para cubrir una ausencia y acortar una distancia (Morales Ladrón 1996; Bouvet 2006). Es un género dialógico por excelencia, aunque pueda establecerse una jerarquía entre emisor y destinatario. En su trabajo, Nora Bouvet afirma la imposibilidad de pensar la propiedad individual del texto contenido en la carta. ¿A quién pertenecen las cartas enviadas? En la voz del emisor está también la del destinatario. Una vez enviada, además, la carta se extraña de su productor, adquiere independencia del remitente y su carácter privado se vuelve potencialmente público. Sin embargo, y a pesar del carácter dialógico de la carta, suelen publicarse aquellas escritas por una figura conocida, y pocas veces aquellas a las que esta responde (Bouvet 2006). No es la excepción en el caso de Perón, donde se conocen mayormente las cartas por él enviadas que fueron difundidas por sus destinatarios, entregadas a editores y archivistas o publicadas en diarios o revistas político-culturales. En menor medida se conoció la reciprocidad del intercambio epistolar, como sucede en el caso de la correspondencia Perón-Cooke o Perón-Frigerio. La consulta reciente a un archivo que contiene buena parte de los papeles pertenecientes a Perón recuperados tras su exilio en Madrid, permite un acercamiento a correspondencia por él recibida, como el caso de Rodolfo Puiggrós que repasaremos en breve.

Al revisar parte del epistolario, se puede comenzar a visualizar cómo Perón organizó lo que llamó la "conducción estratégica" desde su exilio. Distintas personas, algunas de ellas prácticamente desconocidas, tenían a su cargo algún asunto del cual informaban regularmente al líder. Resulta claro que uno de los temas que le preocupaban a Perón fue, justamente, el lograr sumar a la juventud, y entre ella a los universitarios, a la causa de su regreso.

Esto último puede ser observado tempranamente en el intercambio epistolar mantenido en octubre de 1959 entre Perón y Sebastián Borro, líder sindical peronista que encabezó la toma al frigorífico Lisandro de la Torre ese mismo año (James 2013, pp.158-166). En una carta de más de tres carillas escritas a máquina, en las que Borro le transmite a Perón cuestiones ligadas a la huelga que ya llevaba más de ocho meses, añade el gremialista que uno de sus propósitos consistía en "unir a los estudiantes y trabajadores", por lo que se dispuso a participar de diversas mesas redondas en distintas

\footnotetext{
41 "Delegados interventores en Derecho y en Farmacia". La Nación, 2 de junio de 1973.
} 
universidades, y una reunión en Plaza Once con dirigentes gremiales y estudiantiles. La descripción que realiza Borro es la de acalorados debates, pero también de aplausos ante sus intervenciones en las que asume un lugar de peronista y combativo. Lo que más parece sorprenderle es el apoyo de algunos sectores del movimiento estudiantil de tendencia antiperonista: "Ahí comprobé que el Peronismo ya había entrado en la F.U.B.A.". 42

En su respuesta de dos carillas, poco tiempo más tarde, Perón habla muy poco de la toma del frigorífico y casi toda la carta está destinada a la reorganización del peronismo y en particular a la cuestión de la juventud y los universitarios:

Lo felicito por sus actividades peronistas en el estudiantado universitario que demuestran que Usted ha penetrado justamente la importancia que los muchachos estudiantes tienen en los movimientos revolucionarios del tipo que nosotros debemos realizar. Como observará en las directivas que por este correo remito, hay dedicado un capítulo, precisamente, a los estudiantes. En los momentos actuales, nadie puede ofrecer al idealismo juvenil lo que el Justicialismo, y es lógico que nosotros debamos aglutinar en el futuro a la juventud argentina y en especial a la juventud universitaria. ${ }^{43}$

Como puede verse, y aunque restaban varios años para que la peronización de los universitarios fuera algo más palpable, ya en 1959 aparece ella como un propósito en la letra del líder justicialista. Pero será avanzada la década del sesenta que las referencias de Perón y los peronistas a la cuestión universitaria se vuelven más recurrentes.

Entre 1966 y 1967 aparecen menciones a grupos universitarios en correspondencia con Perón de Pablo Vicente y Bernardo Alberte, ambos ex militares peronistas cumpliendo funciones de organización de la Juventud Peronista. La federación de agrupaciones peronistas FANDEP aparece mencionada en reiterados casos, aunque no exenta de conflictos con la "conducción táctica" del peronismo. ${ }^{44}$ También informa Vicente a Perón acerca de la incorporación de bibliografía peronista en la carrera de Sociología de la Facultad de Filosofía y Letras, en referencia a la cátedra de Justino O'Farrel: "Entiendo que es algo sumamente positivo y de gran valor". ${ }^{4}$

\footnotetext{
${ }^{42}$ Sebastián Borro a Juan D. Perón. Buenos Aires, $1^{\circ}$ de octubre de 1959. Juan Domingo Perón Papers, Box 1, Hoover Institution Archives, Stanford University.

${ }^{43}$ Juan D. Perón a Sebastián Borro. Ciudad Trujillo, 20 de octubre de 1959. Juan Domingo Perón Papers, Box 1, Hoover Institution Archives, Stanford University

${ }^{44}$ Por ejemplo, en Bernardo Alberte a Juan D. Perón. Buenos Aires, 5 de septiembre de 1967. Juan Domingo Perón Papers, Box 2, Hoover Institution Archives, Stanford University; y en Pablo Vicente a Juan Domingo Perón, Montevideo, 25 de diciembre de 1966. Juan Domingo Perón Papers, Box 6, Hoover Institution Archives, Stanford University.

${ }^{45}$ Pablo Vicente a Juan Domingo Perón, Montevideo, 26 de septiembre de 1967. Juan Domingo Perón Papers, Box 6, Hoover Institution Archives, Stanford University.
} 
En el siguiente fragmento epistolar fechado en 1969 por un funcionario universitario de la primera década peronista, se puede apreciar la continuidad del fenómeno que analizamos:

Cumpliendo con vuestro pedido de tratar de revivir los contactos universitarios a futuros efectos, he comenzado semanalmente a fijarme varias entrevistas -con graduados de nuestra época y profesores; ellos me van llevando a graduados más jóvenes y así voy remontando hasta la actualidad. Sin pretender que sea definitivo, me voy encontrando con una sorpresa. La juventud es, lógicamente, progresista. Hay más peronistas de los que yo, honestamente, me imaginaba. E inclusive los izquierdistas, por así llamarlos genéricamente, tienen un sentido nacional que asombra maravillosamente. ${ }^{46}$

Por un lado, se percibe un crecimiento del peronismo universitario, y por el otro, el carácter "nacional" de sus cosmovisiones, aun en los no peronistas. Peronización y nacionalización se sugieren relacionadas pero diferenciadas, de modo similar al que hemos visto en otro tipo de fuentes.

El siguiente fragmento proviene de un abogado que ejercía como profesor en universidades privadas, y que también se muestra sorprendido:

Sólo los verdaderos peronistas somos cada día más optimistas. Y ello así, por cuanto cotidianamente advertimos que su número aumenta en forma prodigiosa. Ese fenómeno lo advierto yo en el ámbito de las varias universidades privadas en las que soy Profesor. Días pasados al concurrir a la Universidad Católica de Mar del Plata (...) con gran alegría me encontré con las paredes empapeladas con fotografías suyas e inscripciones a favor del peronismo. He visto -y créame que no exagero el juicio- pegados afiches peronistas en las paredes de la Catedral de Mar del Plata, que dan frente a la Universidad. ${ }^{47}$

Si bien no contamos con el intercambio epistolar completo que muestre la reacción de Perón a estas últimas cartas, algunas por él escritas muestran cómo percibió la llamada peronización de los sectores medios. En una conocida carta a Juan José Hernández Arregui, por ejemplo, Perón se refiere a los intelectuales, entre ellos el mismo Arregui y miembros de las Cátedras Nacionales, que según su punto de vista estarían dando un valioso aporte al conocimiento del peronismo. Al mismo tiempo, observa Perón, que "el Peronismo está despertando entre los intelectuales". ${ }^{48}$ En otra carta, que

\footnotetext{
${ }^{46}$ Fernando Raúl Mitjans a Juan D. Perón. Buenos Aires, 28 de febrero de 1969. Juan Domingo Perón Papers, Box 1, Hoover Institution Archives, Stanford University. El resaltado es nuestro.

${ }^{47}$ José Sarrabayrouse Varangot a Juan D. Perón. Buenos Aires, 25 de octubre de 1971. Juan Domingo Perón Papers [Box 5] Hoover Institution Archives, Stanford University. El resaltado es nuestro.

${ }^{48}$ Juan D. Perón a Juan J. Hernández Arregui. Madrid, 10 de diciembre de 1969. En Perón, Correspondencia
} 
es una respuesta a Antonio Caparrós, psicoanalista proveniente del comunismo, Perón escribe sobre la "incorporación de fuertes grupos de intelectuales a la causa [de la liberación nacional]". ${ }^{49}$

Otro interlocutor de Perón, que también se ocupó especialmente de la relación con jóvenes universitarios, le escribía:

La juventud responde y mucho querido General. Días pasados, ante el anuncio de que se hablaría sobre un tema candente vinculado al Peronismo, que estuvo a cargo de Arturo Jauretche -aún y a pesar de tratarse de él y aunque estuvo bien, se juntaron en el aula magna 1.500 alumnos y a cada alusión concreta sobre Usted o el Movimiento prorrumpían en aplausos. El domingo pasado visitándome en mi casa el Profesor Adjunto de Economía Dr. De Leyes -que estuvo presente y que no es Peronista aunque va entrando por el aro con sus 35 años-, me contaba entusiasmado de esa presencia y ese fervor. Indiscutiblemente, lo que no se pudo tener antes desde el Oficialismo, lo tenemos ahora espontáneamente y por vía de una fijación personal de posición, en total libre albedrío.

Es decir que ahora no podrán decir que era la propaganda oficial la que juntaba a la muchachada. ${ }^{50}$

La carta está escrita por Pedro Michelini, abogado platense que actuó como apoderado de Perón. El intercambio epistolar entre ambos se desarrolló con creces y de forma ininterrumpida al menos desde 1965 y hasta 1972. En una oportunidad, le hizo llegar a Perón una comunicación de una de las agrupaciones universitarias peronistas surgidas luego del golpe de Estado de 1966, la FURN de La Plata. En 1970, Perón le responde con signos de entusiasmo:

Es auspicioso para la causa de la liberación de nuestra Patria y de su Pueblo que la juventud universitaria haya comenzado a comprender la realidad de nuestra situación y la necesidad de ponerse a luchar por resolverla. Han sido necesarios muchos dolores, el azote de la dictadura militar y quince años de simulación insidiosa, para que nuestra juventud pudiera comprenderlo (...). ${ }^{51}$

\footnotetext{
1, Ed. Corregidor, Buenos Aires, 1983.

49 Juan D. Perón a Antonio Caparrós. Madrid, julio de 1969. En Perón, Correspondencia 1, Ed. Corregidor, Buenos Aires, 1983

${ }^{50}$ Pedro Michelini a Juan D. Perón. Buenos Aires, 23 de noviembre de 1967. Juan Domingo Perón Papers, Box 4, Hoover Institution Archives, Stanford University. El destacado es nuestro.

${ }^{51}$ Carta de Perón a los "compañeros de la Federación Universitaria de la Revolución Nacional, Secretaría Universitaria de la Juventud Peronista de La Plata”, Madrid, 24 de junio de 1970. En Perón,
} 
Perón observa el proceso de mayor "comprensión" por el peronismo, pero no adjudica la incomprensión previa a la "autocrítica" de la que daban cuenta otros testimonios. De haber existido, es difícil suponer que estuviera dispuesto a realizarla en público. ${ }^{52} \mathrm{El}$ peso de la responsabilidad por la mirada de los jóvenes universitarios durante el primer peronismo es colocado en los universitarios mismos, en igual medida que el mérito por la mutación observada en los años sesenta:

Yo nunca he podido comprender cómo un joven argentino puede estar con las fuerzas obscurantistas de la reacción, con la entrega del país (...). Pero aún menos lo podía comprender de la juventud universitaria que, como tal, debe ser la juventud esclarecida. Indudablemente, ha existido una grave incomprensión y me alegra saber por lo que Ustedes me dicen, que existe una gran reacción estudiantil en el sentido propugnado por nosotros y el mérito de ello debo asignarlo a Ustedes y al incesante trabajo que realizan, por todo ello les hago llegar mi enhorabuena. ${ }^{53}$

Escribe también que "el mundo actual se agita en una revolución y, dentro de él, el Continente Latinoamericano se ha lanzado auspiciosamente a una 'guerra revolucionaria' por la liberación de los pueblos y las respectivas patrias, con postulados muy cercanos a los del Justicialismo". Insiste en el lugar de la "nueva generación juvenil argentina" para acelerar ese proceso, generación ahora "esclarecida por la experiencia". 54

Insistimos aquí una vez más: no se trata de develar si era una observación cierta o engañosa la que hacían Perón y los peronistas, sino de tener en cuenta la existencia de este fenómeno según su propio punto de vista, lo cual no deja de ser un dato de relevancia. No conocemos la carta que le envió FURN a Perón motivando su respuesta, pero sí estamos en condiciones de afirmar que, junto a los casos que ya hemos documentado, en no pocas ocasiones recibía Perón información sobre lo que sucedía en las universidades y otros ámbitos juveniles. Uno de esos canales fue la correspondencia que le enviaba Rodolfo Puiggrós, quien iba a ser elegido rector de la universidad más importante del país a la hora de impulsar un proyecto de universidad donde el movimiento estudiantil, y especialmente el peronista, iba a adquirir protagonismo.

\section{La "peronización masiva" de los estudiantes en la correspondencia de Puiggrós a Perón}

Como hemos desarrollado en un trabajo previo, Puiggrós se ocupó desde 1945 de una tarea que consideraba crucial: dotar al peronismo de teoría revolucionaria. $\mathrm{Su}$

Correspondencia 1, Ed. Corregidor, Buenos Aires, 1980, 203-206. El destacado es nuestro.

${ }_{52}$ Perón sabía que su correspondencia se convertía frecuentemente en material de difusión: el carácter potencialmente público del género epistolar debe ser una vez más tenido en cuenta (Bouvet 2006).

${ }^{53}$ Carta de Perón a los "compañeros de la Federación Universitaria de la Revolución Nacional, Secretaría Universitaria de la Juventud Peronista de La Plata", Madrid, 24 de junio de 1970. En Perón, Correspondencia 1, Ed. Corregidor, Buenos Aires, 1980, 203-206. El destacado es nuestro.

${ }^{54}$ Ibidem 
propósito era izquierdizar al peronismo y peronizar a las izquierdas (Friedemann, 2014). Por ese motivo, sus expresiones relativas a la peronización de los universitarios estarán teñidas por el tono de una exitosa labor emprendida.

En 1961 se había instalado en México, por las dificultades económicas atravesadas desde 1955. Allí dictaba clases en la UNAM, colaboraba en un periódico y desarrolló una intensa producción historiográfica. Pero a comienzos de 1966 no le renovaron su permiso de residencia y se radicó nuevamente en la Argentina. Rápidamente continuó su militancia en el peronismo y comenzó a coordinar grupos de estudio. En 1971, en un reportaje que le realizaron para la revista Envido, el entrevistador lo interpeló sobre "la incorporación de sectores provenientes de partidos tradicionales y de la izquierda al movimiento de liberación nacional”. En su respuesta, Puiggrós se refirió a la "peronización masiva de la juventud" ${ }_{55}$, pero no era la primera vez que este asunto le ocupaba la atención. Antes de ello, se lo había manifestado por correspondencia a Juan Domingo Perón en reiteradas ocasiones. En una carta del 15 de enero de 1968, le escribió:

A mi regreso a la Argentina, después de casi seis años de ausencia, nada me impresionó tanto como el notable vuelco hacia el peronismo de la juventud estudiantil, sector que, por razones profesionales, es el que estoy en condiciones más directas de captar. (...) Numerosos estudiantes (universitarios y secundarios; los pibes que al llegar a los quince años iban hacia los partidos de izquierda, hoy van en busca de la salida revolucionaria de masas en el peronismo) se me acercaron para preguntarme Qué hacer. Dimos juntos los primeros pasos a través de cursos, algunos públicos (...) y otros privados en mi casa o en sindicatos de la capital y del interior. Uno de ellos, en La Plata, congregó durante varios meses de 1967 a jóvenes obreros y estudiantes, Pero llegó un momento en que claridad teórica y política desembocó en un llamado apremiante a la acción. Querían luchar, ser protagonistas del gran cambio histórico que madura en nuestro país. ${ }^{56}$

En lo que resta de la carta, detalla el desarrollo de "Comandos Revolucionarios Peronistas" iniciados por doce de esos compañeros y bajo la órbita del Mayor Bernardo Alberte. Según se desprende del texto, Puiggrós habría estado involucrado en la conformación de grupos universitarios que dieron un salto a la lucha armada.

En otra epístola, el 21 de marzo de ese mismo año, Puiggrós vuelve sobre lo que llamó un proceso de peronización:

\footnotetext{
${ }^{55}$ Tomás Saravi. Reportaje a Rodolfo Puiggrós. Envido No 4, septiembre 1971, p. 44.

${ }^{56}$ Rodolfo Puiggrós a Juan D. Perón. Buenos Aires, 15 de enero de 1968. Juan Domingo Perón Papers, Box 5, Hoover Institution Archives, Stanford University. El subrayado es del original y los destacados son nuestros.
} 


\section{Impresiona el vuelco de los estudiantes y los profesionales jóvenes, sectores que hasta hace poco militaban, en su gran mayoría, en los partidos liberales, especialmente en los de izquierda. La experiencia de los gobiernos posteriores a 1955 y los cambios en el ámbito mundial les abren los ojos. Y si todavía muchos no se atreven a zambullirse en el movimiento peronista, todos lo entienden y justifican como fenómeno histórico-social. ${ }^{57}$}

Como puede verse, Puiggrós también distingue entre quienes se peronizan y aquellos que, sin "zambullirse en el movimiento peronista", lo comprenden de una manera novedosa. Pero se referirá más a la peronización que a la nacionalización:

El proceso de peronización masiva del estudiantado $-(\ldots)$ que se acentúa día a día- constituye una prueba concluyente de la tendencia insurreccional en marcha en la Argentina. No sorprende el peronismo de los jóvenes obreros que nacieron $\mathrm{y}$ se formaron en hogares peronistas (...). En cambio, la peronización de los estudiantes - hijos de la clase media o de las clases altas- implica una significativa ruptura generacional. Los intelectuales peronistas, que diez años atrás no tenían acceso a las tribunas estudiantiles, son hoy los más buscados por los estudiantes. ${ }^{58}$

Esta última carta resulta de una magna extensión en la que Puiggrós recupera una y otra vez temáticas vinculadas a la participación de la juventud en el peronismo. Su intenso intercambio epistolar se complementaba con otros encuentros: Perón iba a recibir a Puiggrós en Madrid en reiteradas ocasiones y le escribiría un prólogo a uno de sus libros (Puiggrós, 1971). Diversas fuentes coinciden en afirmar que fue Perón quien lo eligió rector de la UBA en $1973^{59}$, e incluso que ya en los años sesenta le había prometido el rectorado en caso de retornar al gobierno (Puiggrós, 2010). La organización Montoneros y la Juventud Universitaria Peronista iban a apoyar con fuerza dicho nombramiento. Una vez desplazado del cargo, en un contexto de creciente persecución sobre la izquierda peronista, Puiggrós se exiliaría una vez más en México, perseguido por la triple A. Ingresaría al Movimiento Peronista Montonero en 1977, falleciendo en 1980 en La Habana, Cuba. ${ }^{60}$

\footnotetext{
${ }^{57}$ Rodolfo Puiggrós a Juan D. Perón. Buenos Aires, 21 de marzo de 1968. Juan Domingo Perón Papers, Box 5, Hoover Institution Archives, Stanford University. El destacado es nuestro.

${ }^{58}$ Rodolfo Puiggrós a Juan D. Perón. Buenos Aires, 27 de diciembre de 1970. Juan Domingo Perón Papers, Box 5, Hoover Institution Archives, Stanford University. El destacado es nuestro.

${ }^{59}$ Diversos testimonios recogidos para nuestra investigación doctoral entre 2008 y 2013 . Uno de ellos indica que la elección fue realizada entre una terna propuesta por Montoneros. Los testimonios escritos de Jorge Taiana y de Adriana Puiggrós coinciden en afirmar la centralidad de Perón en dicha designación (Taiana, 2000; Puiggrós, 2010).

${ }^{60}$ Para un desarrollo de la trayectoria de Puiggrós nos remitimos a un trabajo previo (Friedemann, 2014) y a dos biografías de diferente registro (Acha 2006; Puiggrós, 2010).
} 


\section{A modo de cierre}

Entre 1955 y 1973, la desperonización proyectada por gobiernos civiles y militares se topó con la persistente identidad peronista en las clases trabajadoras y con múltiples revisiones sobre el peronismo que se manifestaban novedosas por parte de los sectores medios. Relecturas del pasado peronista, que a la vez se constituían en proyecciones futuras de un movimiento en continua reconfiguración. Perón, por su parte, se ocupó desde el exilio por reducir la distancia que lo separaba de la política nacional y del movimiento, asumiendo lo que denominó una "conducción estratégica". Si la "táctica" quedaba en manos de las dirigencias locales, la escritura epistolar tejía un puente con Madrid manifestando el típico "juego de presencias/ausencias" que forma parte de este género dialógico de escritura (Morales Ladrón, 1996: 286).

Una de las transformaciones que el peronismo atravesó en los años sesenta ha sido frecuentemente visitada por bibliografía: se trata de la llamada peronización y nacionalización de los sectores medios, y entre ellos, los universitarios. Docentes, estudiantes e intelectuales habrían atravesado durante aquellos años un proceso de mayor comprensión por cierto nacionalismo y por el peronismo, cuando no directamente un pasaje militante a sus organizaciones. Una serie de estudios pioneros sobre el tema sentaron las bases sobre las que se construyeron investigaciones más o menos acotadas a casos particulares. Múltiples organizaciones peronistas surgieron luego del golpe de Estado de 1966 en las universidades, algunas de ellas muy pequeñas, y con intentos de articulación no siempre exitosos. A comienzos de 1973, casi todas confluirán en la nueva Juventud Universitaria Peronista, creada por Montoneros como organización de superficie para el ámbito universitario. En esa coyuntura, la JUP será protagonista de un proyecto de reforma universitaria que resultará inconclusa y finalmente derrotada.

Para dar cuenta de ese proceso, en los trabajos sobre el tema sobresale la utilidad analítica de la categoría de peronización. Sin embargo, la validez de la misma ha sido puesta en cuestión desde una serie de trabajos centrados en las luchas callejeras protagonizadas por el movimiento estudiantil. En ellos se afirma que la peronización no fue tal, sino que el fenómeno de 1973, en el que el peronismo universitario ganó las elecciones en casi todos los centros de estudiantes, fue un fenómeno disruptivo.

Sin negar la importancia que dicho debate puede suscitar para un mayor conocimiento sobre el tema, propusimos una lectura no dicotómica del mismo que no ha sido suficientemente explorada. Si bien no consideramos prudente negar la existencia misma del proceso de peronización, ni soslayar la potencialidad analítica de dicha categoría, propusimos un enfoque que atienda a la perspectiva de algunos sectores del peronismo y del propio Perón, entendiendo a este movimiento no como una entidad esencial, siempre igual a sí misma. Por el contrario, las reconfiguraciones que lo atravesaron durante los años sesenta permiten evaluar la performatividad de los discursos y acciones de Perón y los peronistas. En otras palabras, se trata de un movimiento político que se transformó a sí mismo y una de esas mutaciones que los propios actores advirtieron, mientras operaban sobre ella, tenía que ver con la llamada peronización de los universitarios. En tanto observación nativa, es posible para el analista historizar sus 
usos dejando en suspenso el propósito de evaluar su pertinencia, sin menosprecio de que esta última examinación sea igualmente válida desde otros enfoques.

Por razones de espacio, nos restringimos a un conjunto delimitado de actores, pero proyectamos ampliar el corpus empírico en futuros trabajos. La selección incluyó a un grupo de intelectuales que ejercieron un rol destacado en la formación teórica y política de los jóvenes universitarios, a través de libros, conferencias, grupos de estudio, y como en el caso de las Cátedras Nacionales, también en las aulas de la Facultad de Filosofía y Letras. El caso de Rodolfo Puiggrós adquiere mayor relevancia para nuestro trabajo. Luego de haber insistido durante varios años de comunicación directa con Perón en la potencialidad que albergaba la "peronización masiva de la juventud", fue designado rector de la Universidad de Buenos Aires en 1973. La mirada de Perón sobre ese mismo asunto, a través del intercambio epistolar que emprendió desde el exilio, permite comenzar a reflexionar sobre la importancia que le otorgó el líder del peronismo a la cuestión universitaria y a la necesidad de contar con el apoyo de los sectores medios para la causa de su regreso al país. Testimonios de actores ligados al Ministerio de Cultura y Educación entre 1973 y 1974, complementan un acercamiento al tema y reafirma el propósito, en buena medida frustrado, de emprender un proyecto educativo y cultural que, debía estar "más a la izquierda que el resto" ${ }^{61}$ Como sugerimos en apartados iniciales de este artículo, es difícil suponer que se hubiera ensayado un proyecto universitario con fuerte protagonismo estudiantil, y especialmente de la izquierda peronista, si la generación mayor que tuvo a su cargo la designación de autoridades y ejecución de propuestas no hubiera observado con beneplácito una creciente peronización de los universitarios durante los años sesenta. Que dicho proyecto de reforma haya sido derrotado y rápidamente interrumpido no significa que no merezca ser atendido en su particularidad. El resultado del proceso analizado no puede constituir una variable explicativa de su desarrollo previo.

\section{Referencias bibliográficas}

Acha, O. 2009. Historia crítica de la historiografia argentina: las izquierdas en el siglo $X X$, Buenos Aires: Prometeo.

Acha, O. 2006. La nación futura: Rodolfo Puiggrós en las encrucijadas argentinas del siglo XX, Buenos Aires: Eudeba.

Altamirano, C. 1992. Peronismo y cultura de izquierda (1955-1965). College Park, Latin American Studies Center, University of Maryland., (6).

De Amézola, G. 1999. "El caso del realismo insuficiente. Lanusse, la Hora del Pueblo y el Gran Acuerdo Nacional”. En: Pucciareli, A. ed. La primacía de la política. Lanusse, Perón y la Nueva Izquierda en tiempos del GAN. Buenos Aires: Eudeba, pp. 57-116.

\footnotetext{
${ }^{61}$ Según las palabras del hijo y secretario privado del ex ministro Jorge A. Taiana. Entrevista realizada por el autor a Jorge Taiana (h.) el 28 de abril de 2011.
} 
Anchou, A. 2007. "De marxistas a peronistas: los militantes del FEN y la conformación de la OUTG". En: XI Jornadas Interescuelas/Departamentos de Historia. Departamento de Historia. Facultad de Filosofía y Letras. Universidad de Tucumán, San Miguel de Tucumán. Available at: http://cdsa.aacademica.org/000108/644.pdf [Accedido junio 26, 2017].

Barletta, A.M. 2000. "Universidad y política. La peronización de los universitarios". En: LASA Proceedings.

Barletta, A.M. \& Tortti, M.C., 2004. "Desperonización y peronización en la universidad en los comienzos de la partidización de la vida universitaria”. En: Krotsch, P. ed. La universidad Cautiva. La Plata: Ediciones Al Margen.

Bertoletti, J. 2010. Montoneros: de la movilización a la Organización. Un caso paradigmático de militarización. Universidad Nacional de San Martín, Argentina.

Besoky, J. L. 2013. "La derecha peronista en perspectiva". En: Nuevo Mundo Mundos Nuevos, (Current issues, Online since 24 May 2013). Available at: 10.4000/ nuevomundo. $65374 \% 0 \mathrm{~A} \% 0 \mathrm{~A}$.

Bonavena, P. 2014. "Los estudiantes universitarios peronista. Del golpe de Onganía a los «azos» del ‘69”. En: $V^{\circ}$ Jornadas de Estudio y Reflexión sobre el Movimiento Estudiantil Argentino y Latinoamericano. Mar del Plata, Argentina.

Bonavena, P. \& Millán, M. 2007. “¿Cómo llegó el movimiento estudiantil rosarino al rosariazo de mayo de 1969?". En: Razón y revolución, 17, pp.119-128.

Bouvet, N.E. 2006. La escritura epistolar, Buenos Aires: Eudeba.

Bozza, J.A. 2001. "El peronismo revolucionario. Itinerario y vertientes de la radicalización, 1959-1969”. En: Sociohistórica, (9-10), pp.135-169.

Brennan, J.P. 1996. El Cordobazo: las guerras obreras en Córdoba 1955-1976, Buenos Aires: Sudamericana.

Buchbinder, P. 2005. Historia de las Universidades Argentinas, Buenos Aires: Sudamericana.

Califa, J. 2016. Dos FUA. Controversias entre las distintas líneas políticas estudiantiles nacionales entre 1970 y 1972. En: VI Jornadas de Estudio y Reflexión sobre el Movimiento Estudiantil Argentino y Latinoamericano. Buenos Aires.

Carli, S., 2014. "Entre la formación cultural y la educación política de los estudiantes. Las visiones sobre la universidad del rector Risieri Frondizi y del intelectual Juan José Hernández Arregui (1955-1973)". En: Universidad pública y experiencia estudiantil. Historia, política y vida cotidiana. Buenos Aires: Miño y Dávila.

Ceballos, C. 1985. Los estudiantes universitarios y la politica (1955-1970), Buenos Aires: Centro Editor de América Latina.

Chama, M. 2006. "Peronización y radicalización de grupos de abogados en los años sesenta y principios de los setenta. La labor defensista como práctica militante”. En: Cuestiones de Sociología - Revista de Estudios Sociales, (3), pp.143-168.

Cooke, J.W. 2015. Obras Completas. Tomo III, Buenos Aires: Colihue.

Cooke, J.W. 2014. Peronismo y Revolución. Obras Completas. Tomo V, Buenos Aires: Colihue. 
Dip, N.A. 2017. Libros y alpargatas. Las tramas discursivas y organizativas del proceso de peronización de estudiantes, docentes e intelectuales de la Universidad de Buenos Aires. 1966-1974. Universidad Nacional de La Plata.

Donatello, L.M. 2010. Catolicismo y Montoneros: religión, política y desencanto, Buenos Aires: Manantial.

Friedemann, S. 2017. "De las Cátedras Nacionales (1967-1971) a la Universidad Nacional y Popular de Buenos Aires (1973-1974). Experiencias configuradoras de institucionalidad universitaria". En: Sociohistórica, (39), p.e026.

Friedemann, S. 2014. El marxismo peronista de Rodolfo Puiggrós. Una aproximación a la izquierda nacional, Buenos Aires: Instituto de Investigaciones Gino Germani.

Friedemann, S. 2016a. "La Universidad Nacional y Popular de Buenos Aires (19731974). El peso de la izquierda peronista en la designación de autoridades". En: $V$ Congreso de Estudios sobre el Peronismo (1943-2016). Resistencia.

Friedemann, S. 2015. La Universidad Nacional y Popular de Buenos Aires (19731974). Una reforma universitaria inconclusa. Tesis doctoral en Ciencias Sociales. Universidad de Buenos Aires. Facultad de Ciencias Sociales.

Friedemann, S. 2016b. "Transición a la dictadura durante el gobierno de Isabel Perón . El ocaso de la Universidad Nacional y Popular de Buenos Aires". En: Entramados y Perspectivas, 6(6), pp.1-34.

Georgieff, G, 2009. Nación y revolución. Itinerarios de una controversia en Argentina (1960-1970), Buenos Aires: Prometeo.

Ghilini, A. 2015. Las Cátedras Nacionales y su despliegue editorial : revistas, libros y publicaciones. , pp.0-15.

Ghilini, A. \& Dip, N. A. 2015. "Experiencias de peronización en la Universidad de Buenos Aires entre la dictadura de Onganía y el gobierno de Cámpora (19661973)”. En: Izquierdas, (25), pp.196-209.

Hernández Arregui, J.J. 2011a. La formación de la conciencia nacional, Buenos Aires: Continente.

Hernández Arregui, J.J. 2004. Nacionalismo y liberación, Buenos Aires: Continente.

Hernández Arregui, J.J. 2011b. Peronismo y socialismo, Buenos Aires: Continente.

James, D. 2013. Resistencia e integración. El peronismo y la clase trabajadora argentina, Buenos Aires: Siglo XXI.

Jauretche, A. 1997. Los profetas del odio y la yapa (la colonización pedagógica)., Buenos Aires: Corregidor.

Jauretche, E. 1997. No dejes que te la cuenten: violencia y política en los 70, Buenos Aires: Colihue.

Krotsch, P. 2002. "Los universitarios como actores de reformas en América Latina: ¿han muerto los movimientos estudiantiles?" En: Espacios en Blanco. Revista de Educación, 12.

Laclau, E. 2011. La razón populista, Buenos Aires: Fondo de cultura Económica. 
Lanteri, M. 2010. "El largo proceso de conformación de la Juventud Universitaria Peronista en la Universidad Nacional de La Plata (1960-1973)". En: XVIJornadas Argentinas de Historia de la Educación. Paraná: Sociedad Argentina de Historia de la Educación (SAHE), Facultad de Ciencias de la Educación, Universidad Nacional de Entre Ríos, Paraná.

Lanusse, L. 2005. Montoneros: El mito de sus 12 fundadores, Buenos Aires: Vergara,. Mallimaci, F. y Giorgi, G. 2007. "Nacionalismos y Catolicismos en la Facultad de Filosofía y Letras de la Universidad de Buenos Aires”. En: VII Jornadas de Sociología: Pasado, presente y futuro (1957-2007). Buenos Aires.

Millán, M. 2016. "La Juventud Universitaria Peronista en las memorias de la militancia estudiantil reformista y marxista de la UBA, 1973 - 1976”. En: Historia, Voces y Memoria, (10), pp.49-63.

Morales Ladrón, M. 1996. La dialéctica entre la presencia y la ausencia ficcional del destinatario en el discurso epistolar. 1616, pp.285-296.

Moscona, G. 2010. Peronismo e intelectuales: la experiencia de las Cátedras Nacionales de la Universidad de Buenos Aires en el período 1967-1974. Universidad de Buenos Aires, Facultad de Ciencias Sociales.

Page, J.A. 1984. Perón Una Biografía, Primera parte (1895-1952), Buenos Aires: Javier Vergara.

Ponza, P. 2008. "El Concilio Vaticano II y el ethos revolucionario en la Argentina de los sesenta-setenta". En: Nuevo Mundo Mundos Nuevos.

Puiggrós, A. 2010. Rodolfo Puiggrós. Retrato familiar de un intelectual militante, Buenos Aires: Taurus.

Puiggrós, R.1971. El peronismo: sus causas, Buenos Aires: CEPE.

Ramírez, A. J. 1999. Sociohistórica. Cuadernos del CISH. En: Sociohistórica, 4(5). Disponible en: http://www.sociohistorica.fahce.unlp.edu.ar/article/view/ SHv04n05a08/1926 [Accedido mayo 12, 2017].

Ramos, J.A. 2014. Crisis y resurrección de la literatura argentina, Buenos Aires: Continente.

Recalde, A. y Recalde, I. 2007. Universidad y liberación nacional, Buenos Aires: Nuevos Tiempos.

Reta, M. A. 2009. "El Frente Estudiantil Nacional (FEN): juventud y estudiantado en el proceso contestatario de los años sesenta en Argentina”. En: Antíteses, 2(4), pp.1059-1093.

Reta, M. A. 2008. "Huellas en el camino hacia la peronización: los estudiantes junto al movimiento obrero peronista". En: Nuevo Mundo Mundos Nuevos. Nouveaux mondes mondes nouveaux-Novo Mundo Mundos Novos-New world New worlds.

De Riz, L. 2000. La politica en suspenso, 1966-1976, Buenos Aires: Paidós.

Rubinich, L. 1999. "Los sociólogos intelectuales: cuatro notas sobre la sociología en los años sesenta”. En: Apuntes de Investigación del CECYP, 3(4). 
Ruiz, G. y Vargas, S. 2013. "Juventud, Militancia y Peronización. El caso del Frente Estudiantil Nacional en Rosario en los albores de la década del 70". En: XIV Jornadas Interescuelas/Departamentos de Historia. Departamento de Historia de la Facultad de Filosofía y Letras, Universidad Nacional de Cuyo. Disponible en: http://cdsa.aacademica.org/000-010/549.pdf [Accedido junio 26, 2017].

Sigal, S., 1991. Intelectuales y poder en la década del sesenta, Buenos Aires: Puntosur. Simonetti, M.F. 2002. Tocar el cielo con las manos: La actividad política de la FURN en la UNLP durante 1966-1973. Universidad Nacional de La Plata. Facultad de Humanidades y Ciencias de la Educación. Disponible en: http://www.memoria. fahce.unlp.edu.ar/tesis/te.659/te.659.pdf.

Soprano, G. 2009. "Recorriendo el espinel de la política. Identidades, redes y escenarios políticos nacionales, provinciales y municipales en el peronismo". En: Política $y$ variaciones de escalas en el análisis de la Argentina. Buenos Aires: Prometeo, pp. 145-182.

Taiana, J.A. 2000. El último Perón. Testimonio de su médico y amigo, Buenos Aires: Planeta. Terán, O. 1991. Nuestros años sesentas: la formacion de la nueva izquerda intelectual en la Argentina 1956-1966, Buenos Aires: Puntosur Editores.

Toer, M. 1988. El movimiento estudiantil de Perón a Alfonsín 1, Buenos Aires: Centro Editor de América Latina.

Tortti, M. C. 2007. El viejo partido socialista y los orígenes de la nueva izquierda. Universidad Nacional de La Plata. Facultad de Humanidades y Ciencias de la Educación.

Tortti, M.C. 2002. "La Nueva Izquierda a Principios de los' 60: Socialistas y Comunistas en la Revista CHE”. En: Estudios sociales, 22(1), pp.145-162. 